\title{
A CASE OF CONGENITAL IDIOPATHIC HYPERTROPHY OF THE HEART
}

\author{
BY \\ D. J. CONWAY, M.B., D.C.H. \\ (From the Children's Department, University College Hospital, London)
}

This case is an example of an uncommon malady in which our knowledge of its etiology may be furthered by fully recording each case as it occurs.

The condition is characterized by marked cardiac enlargement and often cardiac failure in an infant or young child, but without evidence of the usual causes of such enlargement.

\section{Case History}

A boy, aged fourteen months, was brought to University College Hospital late one night because the parents were alarmed by his rapid breathing, unusual bouts of screaming, and refusal to eat. Two days previously he had returned by car from a seaside holiday, and after the journey appeared unwell and refused to eat. The following day he was still fretful and rather feverish. He had diarrhoea, and vomited on one occasion. On the day of admission he became more miserable, and his breathing was laboured. He was thirsty, but refused food and had bouts of screaming.

His birth had been normal, and the child had been apparently healthy with no previous illnesses until an attack of measles six weeks before admission. He was the first child of a healthy mother who had been well throughout pregnancy, and had not suffered any earlier miscarriages. The father had had ulcerative colitis for many years. There was no consanguinity between the parents, and no history of heart trouble or sudden deaths in childhood on either side of the family.

On admission the child was noticed to be pale and perspiring but without obvious cyanosis or venous engorgement. The temperature was $100^{\circ} \mathrm{F}$. and the respiration rate 90 per minute. There was slight injection of the left tympanic membrane but the rest of the upper respiratory tract was normal. In the chest the percussion note was normal, the breath sounds were loud at both lung bases, and no adventitious sounds were heard. The heart sounds were normal and the rate 112 per minute. The heart size was not estimated. In the abdomen the spleen was not palpable and there was no ascites. The liver was palpable three fingers below the right costal margin. Other systems were normal. An $x$-ray examination of the chest showed well marked cardiac enlargement (fig. 1) and a faint opacity at the left lung base on the lateral view.
His immediate condition was thought to be an early bronchopneumonia, and sulphamezathine was prescribed. The child died six hours after admission.

Pathology. Necropsy was performed seven hours after death by Professor G. R. Cameron.

The body was that of a fairly well nourished male child looking his age of fourteen months. There was slight oedema of the ankles and legs. The pupils were equal and average in size, and the conjunctivae clear. There were no icterus, palpable glands, skin rashes, or herniae. The lips were not cyanosed. There was little post-mortem staining.

Heart. Its weight was $135 \mathrm{~g}$. (normal 41 g.), and $60 \mathrm{ml}$. of clear, straw-coloured pericardial fluid was found. There was no pericarditis, and little

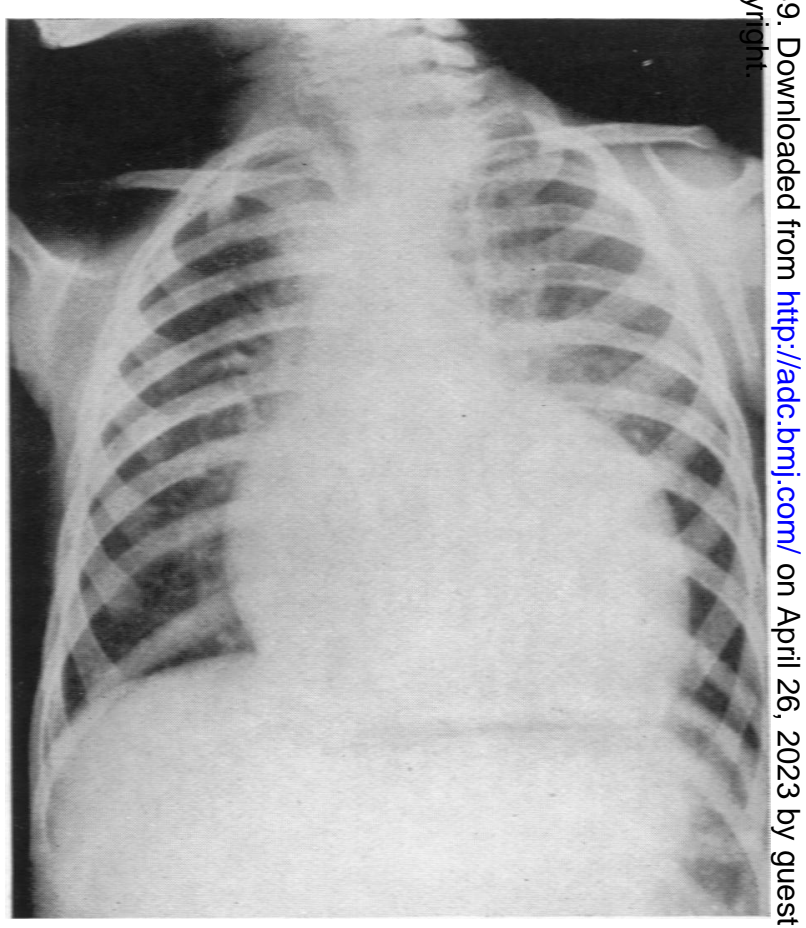

FIG. 1.-Radiograph of chest showing cardiac enlargement. 
epicardial fat. There were numerous small and medium-sized fresh subepicardial haemorrhages at the base posteriorly along the course of the main coronary vessels, and crops of petechiae at the apex posteriorly, also some ecchymoses on the ascending aorta. Hypertrophy and dilatation of the ventricles was very marked, particularly of the left ventricle wall, which was $14 \mathrm{~mm}$. thick, and the right $3.5 \mathrm{~mm}$. (fig. 2). The heart muscle was firm and free from obvious fibrosis. The iodine test for glycogen was negative. The aortic valves were normal. The mitral valves were competent, showing some tiny pin-point firm areas at the margin of the valve flaps. There were similar reddish areas at the edges of the tricuspid valve. The foramen ovale was closed. There was only post-mortem clot in the ventricles. The aorta was free from atheroma throughout. The ductus arteriosus was closed. There was no coarctation. The large veins near the heart contained post-mortem blood clot.

LUNGS. Between 60 and $90 \mathrm{ml}$. of clear fluid were found in both pleural cavities with partial collapse of the right lung. The lungs were greyish

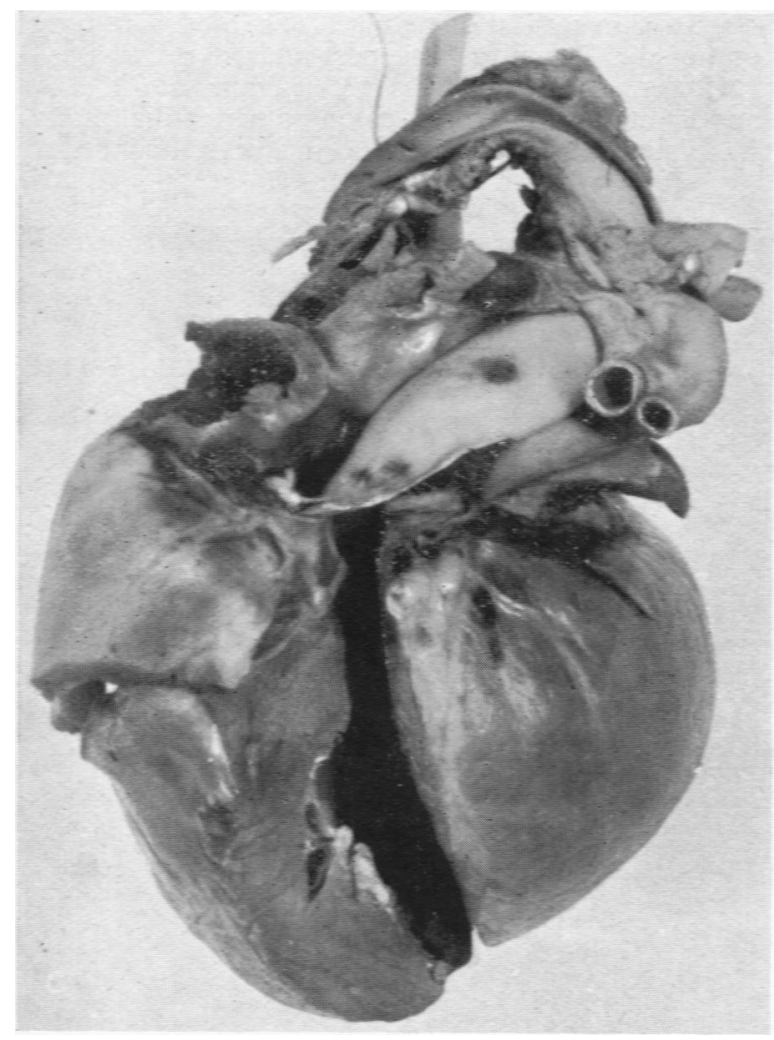

FIG. 2.-Photograph showing extraordinary thickness of the wall of the left ventricle $(14 \mathrm{~mm}$.) compared with that of the right ventricle $(3.5 \mathrm{~mm}$.), and the presence of subepicardial and adventitial haemorrhages. in colour, air-containing, congested, and free from consolidation, with signs of acute bronchitis. The hilar and tracheo-bronchial glands were prominent and fleshy but not grossly enlarged. The trachea contained a little mucopus. The larynx was normal.

LIVER. Weight was $285 \mathrm{~g}$., and the organ was of average size, fatty but firm with no perihepatitis. The hepatic veins and portal vein were normal. The gall bladder was distended containing thick, greenish bile, and the wall was normal. The bile ducts were patent. The pancreas was normal.

SPLEEN. The weight was $25 \mathrm{~g}$. and it was of average size, firm and dark red, with no perisplenitis. The artery and vein were normal.

KIDNEYS. Their weight was $50 \mathrm{~g}$. and they were of average size with a capsule which stripped easily and cleanly, disclosing a dark red, firm, smooth surface, and no cysts. The cortex was broad and the medulla showed a streaky congestion, but the pattern was clear. Small arteries were not thickened. There was little pelvic fat. The tips of the papillae were very red. Both pelves showed congested vessels and a few petechiae. The ureters, bladder, prostate, and genital organs were all normal. There was a little urine in the bladder which contained albumen but no sugar or blood.

Ductless GLANDS. The pituitary, thymus, thyroid, and adrenals were all normal.

Alimentary Canal. The tongue was normal. The nasopharynx was congested with very large soft tonsils. The oesophagus was empty. The stomach contained a moulded milk clot, and the wall was uniformly reddened and smooth. Only a little mucus was present, but no free blood. The first part of the duodenum showed a congested wall. The small and large intestines showed patches of congestion which were not very severe and free from ulceration. The mucous coat of the large intestine seemed swollen. The mesenteric glands were prominent, fleshy and mildly congested, but not very large. There was a moderate amount of fat in the mesentery and omentum. Clear, strawcoloured ascitic fluid $(60 \mathrm{ml}$.) was present.

BraIN. There was slight congestion of the membranes and brain substance with a few petechiae scattered throughout the white matter of the cerebrum and around the dentate nucleus of the cerebellum. No areas of softening were found, and no oedema. The choroid plexus was normal, and the ventricles clear and not dilated. No haemorrhage had occurred in the brain stem and there was no pressure cone. The middle ears were almost dry with no pus. The venous sinuses contained postmortem clot and fluid blood.

BONEs. The red bone marrow in the femurs, ribs, and sternum was ample and no obvious abnormalities were apparent. The cranial bones showed a congenital deficiency in the region of the left occipital bone about $1 \mathrm{~cm}$. above the foramen magnum. The gap in the bone was bridged by a thickened periosteum and dura, so that any herniation of the cerebellar lobe on that side was prevented. 
There was no apparent leakage of cerebrospinal fluid here.

We concluded that this was a case of congenital idiopathic hypertrophy of the heart, associated with bronchitis and bronchiolitis, the latter probably the result of the attack of measles.

Laboratory investigations. The brain, lungs, kidneys, spleen, lymph glands, adrenals, prostate, and several sections from various parts of the intestinal tract were all normal on microscopy.

The liver was of normal architecture without any increase of fibrous tissue in the portal tract or cellular infiltration, and there was no venous congestion. The peripheral liver cells in the lobule were normal but most of the central ones contained some vacuoles. Cloudy swelling was absent. After some two months' fixation in formalin solution a Best's carmine stain showed a very small amount of glycogen in tiny granules in the normal liver cells but not in any of the vacuoles. Though a fat stain was not made, the gross appearance of the liver and the type of vacuoles suggested that there was fatty infiltration.

All the muscle fibres of the heart were much larger than one would expect in a child of this age. In places, giant fibres, twice the thickness of the rest, could be seen. The fibres appeared longer than normal, but these were not measured because of the difficulty in gauging the exact length of the fibres in a section.

In order to show the hypertrophy of the muscle fibres, microphotographs (fig. 3) were taken of the section of this heart and that of another boy of the same age in good general condition, who died after a few days' illness from pneumococcal meningitis. Both sections were taken from the same area of the left ventricle on the anterior surface midway between the apex and the aortic valve.

TABLE

Hypertrophied Heart

Weight, $135 \mathrm{~g}$.

Diameter of most muscle fibres, $30 \mu$.

Diameter of giant fibres, $50-65 \mu$. oval shape. The nuclei in the giant muscle fibres were round and irregular with an easily visible nucleolus, and cytoplasm was abundant and clear in some but dark in others.

The muscle fibres did not show hyaline change, cloudy swelling or fragmentation, nor were they of irregular shape. Heidenhain's iron haematoxylin stain showed normal muscle striation. In places many fibres showed small vacuoles, usually near the nucleus. A Best's carmine stain two months after fixation in formalin solution revealed a small amount of glycogen in the form of small red granules in the fibres, but not in any of the vacuoles. A Sharlach red fat stain demonstrated a normal amount of intracellular fat in fine droplets.

The myocardium was free from interstitial fibrosis and cellular infiltration. The endocardium of the ventricles and auricles was normal, and there was no pathological change in the coronary arteries or their finer branches.

\section{Discussion}

It is well to bear in mind that a frequent cause of apparent cardiac enlargement in childhood is the normal broadening of the heart shadow in expiration. Kypho-scoliosis of the spine and depression of the sternum may flatten or displace the heart making it appear big. Acute and chronic pulmonary disease, may result in a large heart and in cardiac failure. Pulmonary collapse, asthma, or emphysema may lead to this enlargement. A severe illness, such as septicaemia, or the extra load and anoxia of severe anaemia, will also cause an increase in the size of the heart. A very large heart in early childhood is usually due to congenital morbus cordis. In the absence of cyanosis, however, many types can be excluded, and an interatrial septal defect, a large ventricular septal defect, or aneurysm of the pulmonary artery, are unlikely without a cardiac murmur. Palpable femoral pulses would exclude coarctation of the aorta. The anomalous origin of one of the coronary arteries from the pulmonary artery will result in a very large heart, without a heart murmur.

Rheumatic pancarditis is rare under two years of age, but diphtheritic myocarditis is a potent cause of heart enlargement and failure. At necropsy little may be seen beyond dilatation and a flabby appearance, and there is no hypertrophy. Microscopically the pathology is seldom very marked. Diffuse hyaline change with occasional fragmentation in the muscle fibres and fatty degeneration can be found.

There was nothing to suggest that this patient had diphtheria. But heart enlargement and myocarditis have been known to follow a number of other common specific fevers, and this child had had measles, from which he recovered well, six weeks previously. The pathological changes in myocarditis which occur during specific fevers and after poliomyelitis do not show the hypertrophy found in the present case. In these types of myocarditis hypertrophy and atrophy in adult heart muscle give the average diameter of an adult muscle fibre as $31 \cdot 5 \%$. They found that in hypertrophy the size of individual fibres increased but not their number, and that therefore there was no true hyperplasia of muscle fibres. I was not able to estimate in this case whether there was any hyperplasia with increase in the number of muscle fibres.

The nuclei were of a normal vesicular type, but most were more rounded than the usual elongated, 
dilatation with hyaline change and some lymphatic infiltration is found in the myocardium. Myocarditis due to the sulphonamides has been described in which the infiltrating cells are eosinophils and large mononuclear cells. The absence of interstitial cellular infiltrations also excludes trichiniasis.

In Fiedler's isolated myocarditis a diffuse inflammatory change occurs in the myocardium, but as a rule the endocardium and pericardium are normal. The inflammatory cells may be lymphocytes or eosinophils. Some perivascular fibrosis, and occasionally granulomatous necrosis with giant cells, occurs. This condition has been described in children as well as in adults by Everley Jones and Marshal (1948), and Saphir, Wile, and Reingold (1944).

Kugel and Stoloff (1933) reviewed the literature of idiopathic cardiomegaly. One group of these cases showed an interstitial myocarditis characterized by hypertrophy of the ventricular walls, particularly on the left side, thickening of the endocardium of the left ventricle and auricle, and, on cutting the muscle, greyish streaks of atrophied and degenerate muscle could be seen. Microscopically these areas showed replacement by fibrous tissue and round cell infiltration. The majority of these children were under two years old at death, but myocarditis could reasonably be excluded in the present case.

Pallor, or greyish cyanosis, limpness and dyspnoea, venous engorgement and enlargement of the liver, a slight fever and leucocytosis together with enlargement of the heart are the clinical features of paroxysmal tachycardia, but the pulse in the present case was 120 per minute instead of 240 to 300 . The enormous cardiac hypertrophy also excluded paroxysmal tachycardia.

Von Gierke's disease and rhabdomyomatosis of the heart can produce cardiomegaly in young children. The former is characterized by enlargement of the liver, ketonuria, a low blood sugar, infantilism, and manifestations of hypoglycaemia. Also heavy glycogen storage occurs in the liver as a rule, probably due to a disturbance in the enzyme system responsible for the reversible conversion of glucose through glucose-phosphate to glycogen. Only in a few cases is cardiomegaly seen with marked glycogen deposition, and it is suggested that in this variety of von Gierke's disease another part of the enzyme system is at fault, for muscle glycogen is broken down to lactic acid or carbon dioxide and water. The present case did not show an excess of glycogen in the tissues when tested with iodine at necropsy, and very little was seen in the histological sections. Van Creveld (1934) has drawn attention to the observation that glycogen in von Gierke's disease is extraordinarily stable even after a long period in watery fixatives.

In rhabdomyomatosis of the heart, single or multiple yellowish-white, discrete tumours are found in the heart muscle, and in them the muscle fibres are grossly distended and distorted with glycogen. The interstitial tissue is not increased and there is no inflammatory reaction. It is of interest to note that Batchelor and Maun (1945) found tuberose sclerosis of the brain in 50 per cent. of reported cases in their review of rhabdomyomatosis of the heart.

Beri-beri is known to cause a very large heart, oedema, and cardiac failure. The heart wall is usually thin and the myocardium degenerate in places, many muscle fibres being fragmented, spiralshaped or just an amorphous eosinophil mass. Allibone and Baar (1946) described a case occurring in England in a child. There was no history of malnutrition in my case nor is the histology similar.

Kugel and Stoloff (1933) collected seventeen cases from the literature of hypertrophy of the heart without other pathological changes. In eight of these there was enlargement of the individual muscle fibres. Howland (1919) reported five cases with the same condition but in only one were the heart fibres increased in size. Four of their cases showed left ventricular hypertrophy and in the fifth it was bilateral, the right side being more hypertrophied than the left. He referred to two cases reported by Simmonds (1896) and Odendorfer (1906) in which gross hypertrophy of the heart was present in stillbirths. In the present case the diagnosis would appear to be that of idiopathic hypertrophy of the heart.

\section{Summary}

After a short illness with screaming, dyspnoea and anorexia, a child died suddenly from cardiac failure.

Post-mortem examination showed gross enlargement and hypertrophy of the heart, particularly of the left ventricle. Other systems were normal, except for some bronchitis.

Microscopy showed that there was gross hypertrophy of individual muscle fibres without any other pathological change in the heart.

I wish to thank Dr. R. Hardy and Professor G. R. Cameron, F.R.S., for their help, and Dr. B. E. Schlesinger, O.B.E., for allowing me to publish this case.

\section{ReFERENCES}

Allibone, E. C., and Baar, H. S. (1946). Arch. Dis. Child., 21, 76.

Batchelor, T. M., and Maun, M. E. (1945). Arch. of Path., 30, 67.

Creveld, S. Van (1934). Arch. Dis. Child., 9, 9.

Everley Jones, H., and Marshall, A. G. (1948). Arch. Dis. Child., 23, 201.

Howland, J. (1919). "Contributions to Medical and Biological Research dedicated to $\mathrm{Sir} \mathrm{Wm}$. Osler.' New York, Vol. 1, p. 584.

Kugel, M. A., and Stoloff, E. G. (1933). Amer. J. Dis. Child., 45, 828.

Karsner, H. T., Saphir, O., and Todd, T. W. (1925). Amer. J.'Path., 1, 351.

Saphir, O., Wile, S. A., and Reingold, I. M. (1944). Amer. J. Dis. Child., 67, 294. 


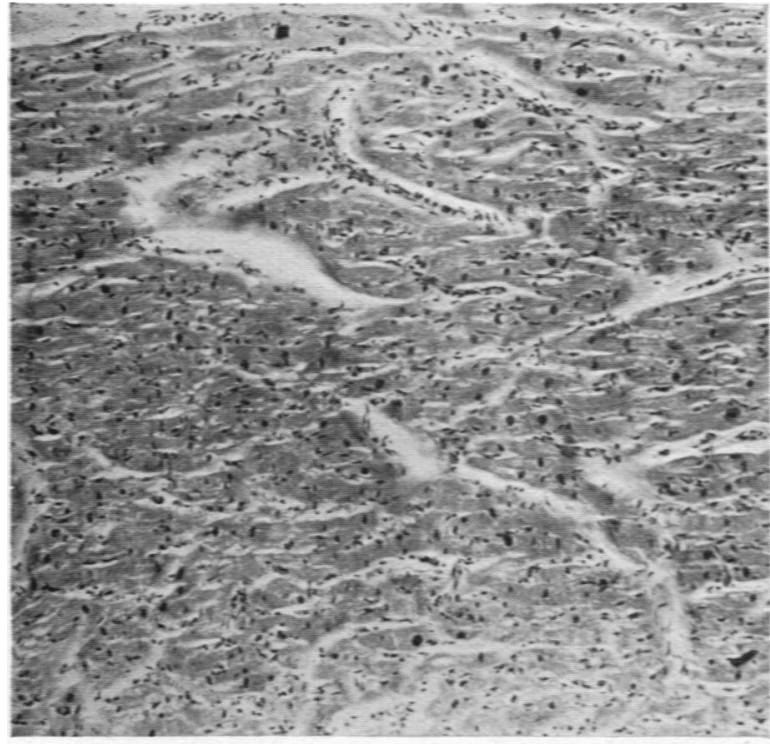

A

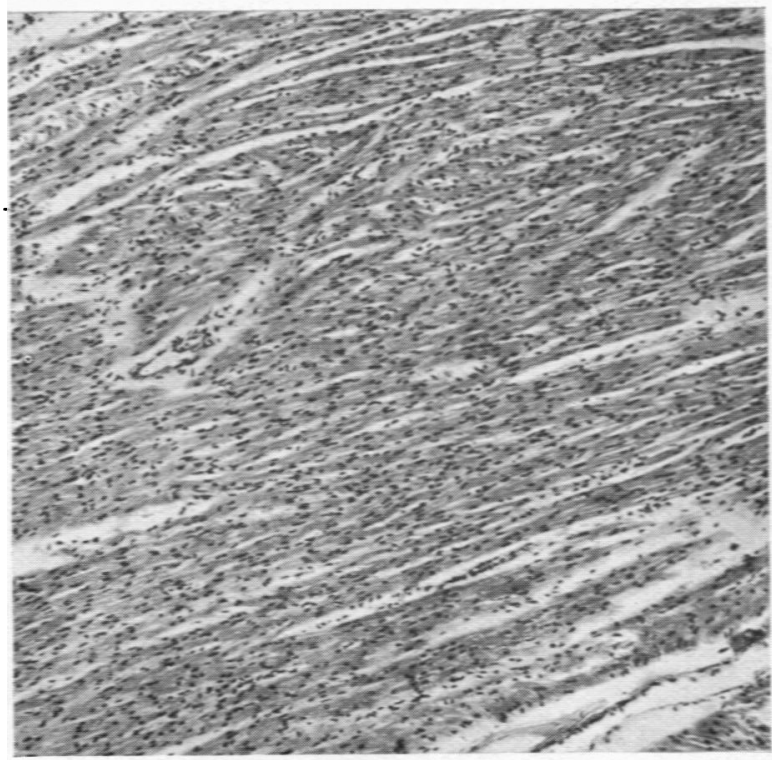

$\mathrm{C}$

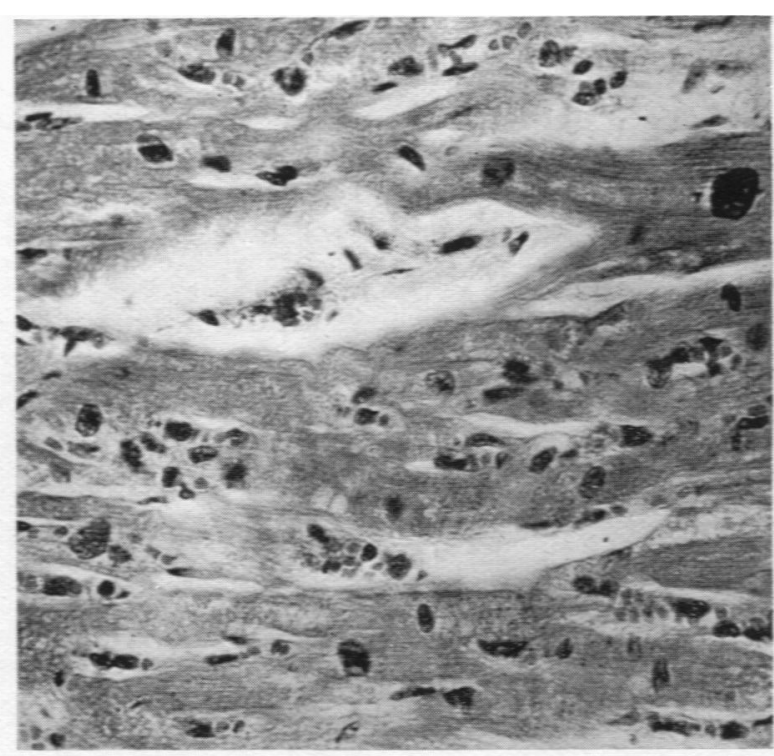

B

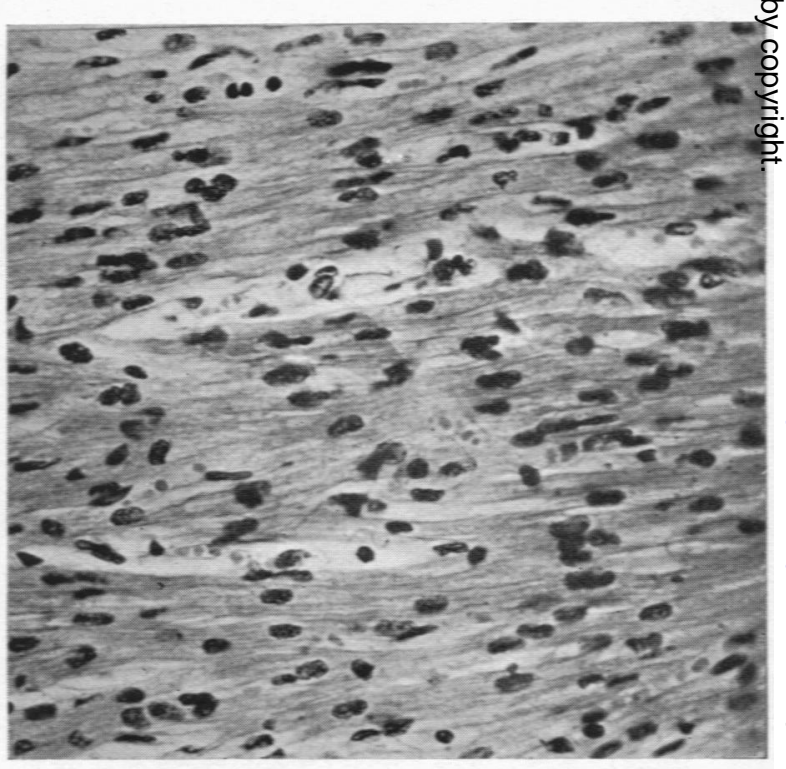

D

Fig. 3.- $A(\times 65)$ and $B(\times 310)$ show sections of left ventricle in the case described of congenital idiopathic hypertrophy of the heart. $C(\times 65)$ and $D(x 310)$ show comparable areas of left ventricle in the control.

Comparison of the low power sections shows that the muscle fibres are thicker in the case of idiopathic hypertrophy of the heart. The nuclei are sparser, and many dark staining large ones can be seen. The high power sections demonstrate better the difference in thickness of the muscle fibre and the variable size of the nuclei between the hypertrophied heart and the control. 